\title{
Variasi penggunaan konjungsi subordinatif rubrik Sosok Harian Kompas
}

Lala Kartika Sandraa,1, Dini Restiyanti Pratiwi b,2

a Prodi Pendidikan Bahasa Indonesia, Fakultas Keguruan dan Ilmu Pendidikan, Universitas Muhammadiyah Surakarta

b Prodi Pendidikan Bahasa Indonesia, Fakultas Keguruan dan Ilmu Pendidikan, Universitas Muhammadiyah Surakarta

1a310170017@student.ums.ac.id ; 2drp122@ums.ac.id

\section{ARTICLE INFO}

\section{Article history}

Received

Revised

Accepted

Keywords

conjunction

subordinating

compass

figure rubric

\section{ABSTRACT}

Conjunction is a conjunction that functions to connect or string words with words, clauses with clauses, sentences with sentences, paragraphs with paragraphs, and so on. Judging from the position of the constituents connected, conjunctions are divided into two, namely coordinating conjunctions and subordinating conjunctions. Subordinating conjunctions are conjunctions that connect two language units unequally. Kompas Daily is the name of an Indonesian newspaper headquartered in Jakarta. In the daily Kompas, there is one rubric, namely the Figure rubric. The Figure Rubric contains a person's life story both in Indonesia and abroad that can inspire and be imitated by readers. The objectives of this study is to describe the form of subordinating conjunctions in the Kompas daily figure rubric. The results in this study are based on Identification obtained 139 data containing subordinating conjunctions. Based on the classification of data, there are 7 types of subordinate conjunctions including: (a) because 43 data were found, (b) conditions were found 5 data, (c) purpose was found 21 data, (d) timing, 29 data was found, (e) presentation was found 15 data, (f) comparison found 7 data, and (g) the final limit found 19 data.

This is an open-access article under the CC-BY-SA license.

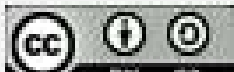

\section{Pendahuluan}

Media massa mempunyai peran strategis sebagai sarana komunikasi untuk menyebarkan informasi kepada masyarakat luas. Media massa berperan untuk menyalurkan informasi kepada khalayak atau masyarakat luas, bisa dalam hiburan, data pribadi, dan kegiatan sosial bagi masyarakat luas [1][2]. Pendapat selanjutnya yang serupa menyatakan bahwa media massa adalah sarana untuk menyampaikan informasi terkini kepada khalayak berupa peristiwaperistiwa yang sedang berlangsung[3]. Selanjuntnya media massa diperuntukan untuk masyarakat luas [4]. Media massa merupakan alat untuk menyalurkan pesan dari sumber kepeda penerima atau masyarakat, dengan memanfaatkan alat komunikasi mekanis televisi, radio, film, maupun surat kabar [5][6]. Dari beberapa pakar diatas maka dapat ditarik kesimpulan bahwa media massa merupakan media yang paling efektik guna menyalurkan berita atau informasi kepada penerima, dengan demikian masyarakat dapat megetahui tujuan dari media massa 
tersebut. Penyampaian informasi kepada masyarakat luas dapat memanfaatkan berbagai macam alat komunikasi mekanis seperti radio, televisi, film, dan surat kabar. Di tengah perkembangan dunia modern terutama perkembangan media massa yang semakin berkembang, dengan begitu media dapat dijadikan alat untuk penunjang kepetingan sebagian orang. Dilihat dari sisi perkembangannya maka penerima atau masyarakat dapat dengan mudah terpengaruh atas informasi atau peristiwa yang telah dipaparkan oleh jurnalis.

Surat kabar menjadi salah satu lembaga pengelolaan informasi yang berpengaruh cukup besar terhadap masyarakat sebagai sumber informasi. Melalui surat kabar masyarakat dengan mudah mendapatkan informasi tentang pemberitaan-pemberitaan yang sedang berlangsung. Surat kabar adalah sarana yang digunakan untuk menyalurkan berbagai macam informasi yang tengah terjadi di masyarakat yang disampaikan secara aktual [7]. Selanjutnya, surat kabar memuat berbagai informasi aktual yang di dapat dari berbagai aspek kehidupan, seperti seni, politik, sosial, ekonomi, kriminal, olahraga, budaya baik dalam negeri atau luar negeri [8]. Harian Kompas termasuk salah satu surat kabar nasional yang menyajikan berbagai informasi yang terbit setiap hari. Kolom yang disajikan memuat berbagai macam informasi yang terjadi di Indonesia. Harian Kompas tidak hanya menjangkau satu wilayah saja, melainkan menjangkau berbagai wilayah di Indonesia. Sehingga harian Kompas mempunyai lebih banyak pembaca dibandingkan surat kabar lainnya. Melihat dari sisi jangkauannya yang cukup luas maka dapat memungkinkan untuk diteliti, baik dari segi kalimat, struktur kalimat, bentuk, pemenggalan dalam kalimat, kata bacaan maupun konjungsinya.

Harian Kompas memiliki berbagai macam jenis rubrik, salah satu yaitu rubrik sosok. Rubrik sosok termasuk salah satu rubrik yang banyak memberikan perhatian oleh para pembacanya. Hal ini karena rubrik sosok memaparkan kiprah seseorang dalam kehidupannya. Berbagai tokoh yang diulas merupakan tokoh yang inspiratif dan kreatif, mulai dari aspek dari seni hingga politik sehingga dapat dijadikan keteladanan bagi pembacanya.

Penyajian informasi yang disajikan di dalam rubrik sosok harian Kompas harus di paparkan secara menarik dengan susunan unsur kebahasaan yang efektif dan sistematis, mulai dari penggunaan kata, kalimat, paragraf, klausa, frasa, dan konjungsi. Unsur kebahasaan berupa konjungsi yang ditemukan dalam rubrik sosok cukup bervariasi. Konjungsi merupakan kategori yang berperan untuk menghubungkan dua kalimat atau dua kata [9][10]. Konjungsi dinamakan sebagai kata sambung, merupakan kategori yang bertugas untuk menghubung dua satuan bahasa yang sederajat: kata, frasa, dan klausa [11][12]. Kata sambung atau konjungsi yaitu kata yang berfungsi untuk menghubung antar bagian kalimat (kata, frasa, dan klausa) serta menghubungkan paragraf satu dengan paragraf lainnya [13]. Berdasarkan defini kedua pakar tersebut maka dapat disimpulkan kata sambung atau konjungsi adalah sataun bahasa yang berperan untuk menyambungkan kata, frasa, dan klausa sehingga membentuk sebuah paragraf yang padu.

Konjungsi memiliki peran untuk mempermudah pembaca memahami informasi yang dipaparkan dalam rubrik tersebut. Terdapat dua macam konjungsi yaitu konjungsi koordinatif dan subordinatif. Dalam rubrik sosok banyak ditemukan jenis konjungsi, terutama pada konjungsi subordinatif [14]. Konjungsi koordinatif merupakan kategori yang digunakan untuk menghubungkan antar bagian kalimat yang tidak setara [15][16]. Konjungsi subordinatif terdapat di depan atau terletak di antara bagian kalimat jika menghubungkan klausa bertingkat, tergantung letak klausa yang mendahului kalimat. Konjungsi subordinatif dibagi menjadi 8 yaitu berfungsi menyatakan sebab, syarat, tujuan, kesewaktuan, penyuguhan, perbandingan, batas akhir, dan pengandaian [17][18]. Dengan demikian, peneliti lebih memfokuskan kajian pada unsur kebahasaan berupa konjungsi subordinatif di dalam rubrik sosok harian Kompas. 
Berdasarkan penjelasan di atas maka peneliti tertarik untuk dilakukan penelitian berjudul "Variasi Penggunaan Konjungsi Subordinatif Pada Rubrik Sosok Harian Kompas". Penelitian ini bertujuan untuk mendeskripsikan penggunaan konjungsi subordinatif pada rubrik sosok harian Kompas. Peneliti memilih rubrik sosok pada harian Kompas menjadi objek penelitian karena tiga hal berikut. Pertama, harian Kompas merupakan salah satu surat kabar yang mempunyai lebih banyak pembaca dari pada surat kabar lainnya karena memiliki jangkauan yang luas di berbagai wilayah Indonesia. Kedua, bahasa yang dipakai pada rubrik sosok harian Kompas mudah dimengerti karena memakai bahasa Indoensia yang baik dan benar. Ketiga, pada rubrik sosok ditemukan delapan jenis variasi konjungsi subordinatif, sehingga rubrik sosok pada harian Kompas menjadi objek yang cocok dengan aspek konjungsi subordinatif yang akan menjadi bahan analisis.

\section{Metode}

Pada penelitian ini menggunakan desain penelitian deskriptif kualitatif. Penelitian deskriptif kualitatif bertujuan untuk mengetahui fenomena-fenomena yang sedang dialami subjek penelitian[19]. Model metode penelitian ini digunakan untuk mendeskripsikan bentuk penggunaan subordinatif pada rubrik sosok yang diakses dari harian Kompas serta untuk mengimplikasikan dalam pembelajaran bahasa Indonesia. Penelitian telah dilaksanakan pada bulan Juli 2020 sampai bulan Maret 2021. Objek dalam penelitian yaitu kalimat-kalimat yang mengandung kata hubung atau konjungsi subordinatif pada rubrik sosok dalam harian Kompas. Penelitian ini menggunakan data berupa kalimat yang terdapat konjungsi subordinatif pada rubrik sosok dalam harian Kompas. Sumber data diperoleh dari kalimat dalam kumpulan rubrik sosok. Teknik dokumentasi, simak, dan catat digunakan untuk mengumpulan data-data yang akan di analisis. Teknik simak adalah teknik yang dipakai untuk mendapatkan data-data yang dilakukan dengan cara menyimak bentuk penggunaan bahasanya, sedangkan teknik catat merupakan teknik yang diterapkan setelah teknik simak [17]. Dalam penelitian ini, peneliti menggunaan triangulasi teori untuk keabsahan dat. Metode padan intralingual digunakan untuk melakukan teknik analisis data penelitian yang bertujuan untuk menganalisis bentuk penggunaan konjungsi subordinatif dalam rubrik sosok harian Kompas.

\section{Hasil dan Pembahasan}

\section{Konjungsi Subordinatif dalam Rubrik Sosok Harian Kompas}

Berdasarkan identifikasi data diperoleh beberapa jenis konjungsi subordinatif yang terdapat dalam rubrik sosok harian Kompas. Hasil identifikasi diperoleh 139 data yang mengandung konjungsi subordinatif. Pengklasifikasian data mengenai konjungsi subordinatif dalam penelitian ini menerapkan teori Chaer yang mengklasifikasikan jenis konjungsi subordinatif berupa: (a) sebab (b) syarat (c) tujuan (d) kesewaktuan (e) penyuguhan (f) perbandingan $(\mathrm{g})$ batas akhir dan $(\mathrm{h})$ pengandaian. Hasil klasifikasi jenis konjungsi subordinatif diuraikan sebagai berkut: 


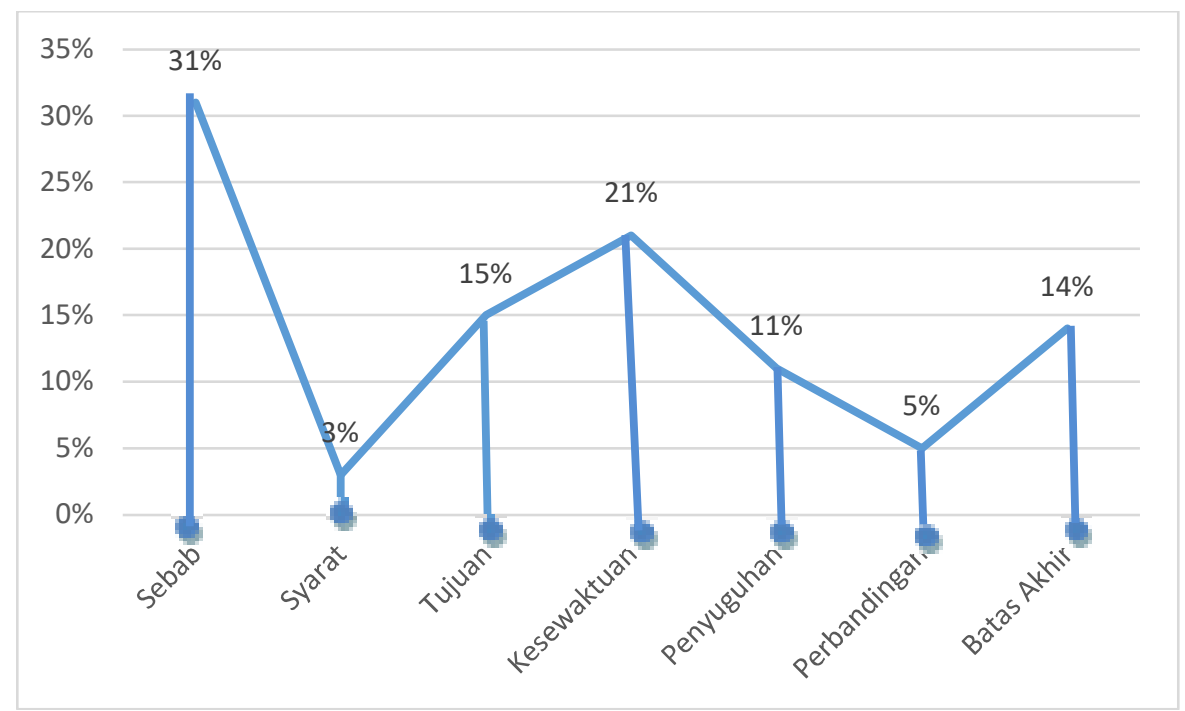

Grafik 1 Konjungsi Subordinatif dalam Rubrik Sosok Harian Kompas

Berdasarkan grafik diatas diketahui dalam rubrik sosok memuat 7 jenis konjungsi subordinat yang meliputi (a) sebab (b) syarat (c) tujuan (d) kesewaktuan (e) penyuguhan (f) perbandingan (g) batas akhir. Hasil masing-masing jenis diuraikan sebagai berikut:

a. Konjungsi yang menyatakan Sebab.

Pada penelitian ini, peneliti menemukan 43 data yang mengandung konjungsi subordinatif yang menyatakan sebab. Berikut beberapa data yang menunjukkan konjungsi subordinatif yang menyatakan sebab:

1) Pria yang disapa Nur ini ingin sekali menolong bayi tersebut namun tidak bisa karena golongan darahnya B. (Kompas/ 01-02-2021/ RPJ)

Pada kalimat diatas terdapat penggunaan konjungsi yang menyatakan sebab (karena), yang digunakan untuk menghubungkan dua bagian kalimat dengan makna menyatakan sebab terjadinya keadaan pada induk kalimat atau klausa utama (Pria yang disapa Nur ini ingin sekali menolong bayi tersebut namun tidak bisa) dan yang dinyatakan oleh anak kalimat atau klausa bawahan (golongan darahnya B).

2) Mereka lebih setuju jika sang anak ikut mengais rongsokan di jalan ketimbang belajar. Sebab, hal itu bisa menghasilkan uang. (Kompas/ 02-02-2021/ FR)

Pada kalimat diatas terdapat penggunaan konjungsi yang menyatakan sebab (sebab), yang digunakan untuk menghubungkan dua bagian kalimat dengan makna menyatakan sebab terjadinya keadaan pada induk kalimat atau klausa utama (Mereka lebih setuju jika sang anak ikut mengais rongsokan di jalan ketimbang belajar) dan yang dinyatakan oleh anak kalimat atau klausa bawahan (hal itu bisa menghasilkan uang)

3) Wawan tidak ingin SLB hanya sekadar menjadi formalitas bagi anak disabilitas untuk mengenyam pendidikan. Ia berupaya agar mereka juga mempunyai kesempatan yang sama untuk melanjutkan pendidikan ke perguruan tinggi. Oleh sebab itu, pada 2017, ia menyurati sejumlah perguruan tinggi negeri di Bandung untuk beraudiensi. (Kompas/ 04-02-2021/ TMY)

Pada kalimat diatas terdapat penggunaan konjungsi yang menyatakan sebab (oleh sebab itu), yang digunakan untuk menghubungkan dua bagian kalimat dengan makna 
menyatakan sebab terjadinya keadaan pada induk kalimat atau klausa utama (ia menyurati sejumlah perguruan tinggi negeri di Bandung untuk beraudiensi) dan yang dinyatakan oleh anak kalimat atau klausa bawahan (Ia berupaya agar mereka juga mempunyai kesempatan yang sama untuk melanjutkan pendidikan ke perguruan tinggi)

b. Konjungsi yang Menyatakan Syarat

Pada penelitian ini, peneliti menemukan 5 data yang mengandung konjungsi subordinatif yang menyatakan syarat. Berikut data yang menunjukkan konjungsi subordinatif yang menyatakan syarat:

1) Mereka lebih setuju jika sang anak ikut mengais rongsokan di jalan ketimbang belajar. Sebab, hal itu bisa menghasilkan uang. (Kompas / 02-02-2021/ FR)

Pada kalimat diatas terdapat penggunaan konjungsi yang menyatakan syarat (jika), digunakan untuk menghubungkan dua bagian kalimat dengan makna menyatakan 'syarat' untuk terjadinya suatu kejadian pada induk kalimat (Mereka lebih setuju) yang disyaratkan pada anak kalimat (sang anak ikut mengais rongsokan di jalan ketimbang belajar)

2) Terapi ini biasanya diberikan kepada anak-anak autisme dan hiperaktif. Jika tidak diterapi akan berdampak pada perilaku yang tidak adaptif," katanya. (Kompas/ 04-022021/ TMY)

Pada kalimat diatas terdapat penggunaan konjungsi yang menyatakan syarat (jika), digunakan untuk menghubungkan dua bagian kalimat dengan makna menyatakan 'syarat' untuk terjadinya suatu kejadian pada induk kalimat (akan berdampak pada perilaku yang tidak adaptif) yang disyaratkan pada anak kalimat (tidak diterapi)

c. Konjungsi yang Menyatakan Tujuan

Pada penelitian ini, peneliti menemukan 21 data yang mengandung konjungsi subordinatif yang menyatakan tujuan. Berikut beberapa data yang menunjukkan konjungsi subordinatif yang menyatakan tujuan:

1) Karena itu, ucap Nur dirinya tidak pernah lelah untuk mengajak orang agar mau menjadi penderma darah. Tujuannya agar misi mulia untuk membantu sesama bisa terus berjalan. (Kompas/ 01-02-2021/ RPJ)

Pada kalimat diatas terdapat penggunaan konjungsi yang menyatakan tujuan (agar), digunakan untuk menghubungkan dua bagian kalimat dengan makna menyatakan tujuan perbuatan atau tindakan yang disebutkan pada induk kalimat (dirinya tidak pernah lelah untuk mengajak orang agar mau menjadi penderma darah) dengan tujuan dilakukannya tindakan yang disebutkan pada anak kalimat (misi mulia untuk membantu sesama bisa terus berjalan)

2) Yayasan ERBE, kini juga tengah memfasilitasi para pemulung agar bisa mendapatkan kartu identitas kependudukan. (Kompas / 02-02-2021/ FR)

Pada kalimat diatas terdapat penggunaan konjungsi yang menyatakan tujuan (agar), digunakan untuk menghubungkan dua bagian kalimat dengan makna menyatakan tujuan perbuatan atau tindakan yang disebutkan pada induk kalimat (Yayasan ERBE, kini juga tengah memfasilitasi para pemulung) dengan tujuan dilakukannya tindakan yang disebutkan pada anak kalimat (bisa mendapatkan kartu identitas kependudukan)

3) Menu sarapan, makan siang, juga malam, berbeda setiap hari. "Biar pengungsi tidak bosan makannya. Masak tiap hari telur. Yang penting itu lauknya gantian, kalau hari ini ayam, besok daging," katanya. (Kompas/ 03-02-2021/ SRY)

Pada kalimat diatas terdapat penggunaan konjungsi yang menyatakan tujuan (biar), digunakan untuk menghubungkan dua bagian kalimat dengan makna menyatakan tujuan perbuatan atau tindakan yang disebutkan pada induk kalimat (Menu sarapan, makan 
siang, juga malam, berbeda setiap hari) dengan tujuan dilakukannya tindakan yang disebutkan pada anak kalimat (pengungsi tidak bosan makannya.

4) Berbagai kesulitan itu tak menghentikan niat Arman untuk melacak naskah kuno Lampung. Baginya, pencarian ini merupakan upaya "menengok" masa lalu guna membangun fondasi masa depan. (Kompas/ 15-02-2021/ VO)

Pada kalimat diatas terdapat penggunaan konjungsi yang menyatakan tujuan (guna), digunakan untuk menghubungkan dua bagian kalimat dengan makna menyatakan tujuan perbuatan atau tindakan yang disebutkan pada induk kalimat (Baginya, pencarian ini merupakan upaya "menengok" masa lalu) dengan tujuan dilakukannya tindakan yang disebutkan pada anak kalimat (membangun fondasi masa depan).

d. Konjungsi yang Menyatakan Kesewaktuan

Pada penelitian ini, peneliti menemukan 29 data yang mengandung konjungsi subordinatif yang menyatakan kesewaktuan. Berikut beberapa data yang menunjukkan konjungsi subordinatif yang menyatakan kesewaktuan:

1) Ide membentuk komunitas donor darah bermula ketika Nurirwansyah (28) melihat Ilham, bayi berusia 4 bulan penderita hidrosefalus, tergolek lemah di RSUP Dr Mohammad Hoesin (RSMH) Palembang, Sumatera Selatan pada 2012. Saat itu, Ilham membutuhkan darah AB untuk memperpanjang hidupnya. (Kompas/ 01-02-2021/ RPJ)

Pada kalimat diatas terdapat penggunaan konjungsi yang menyatakan kesewaktuan (ketika), digunakan untuk menghubungkan dua bagian kalimat dengan makna menyatakan bahwa perbuatan pada klausa yang satu (Ide membentuk komunitas donor darah bermula) berlangsung dalam waktu yang disebutkan oleh klausa kedua (Nurirwansyah (28) melihat Ilham, bayi berusia 4 bulan penderita hidrosefalus, tergolek lemah di RSUP Dr Mohammad Hoesin (RSMH) Palembang, Sumatera Selatan pada 2012)

2) Untuk satu kantung darah merah, para calo darah mematok harga Rp 400.000, sementara satu kantong trombosit Rp 2,5 juta. (Kompas/ 01-02-2021/ RPJ)

Pada kalimat diatas terdapat penggunaan konjungsi yang menyatakan kesewaktuan (sementara), digunakan untuk menghubungkan dua bagian kalimat dengan makna menyatakan bahwa perbuatan pada klausa yang satu (Untuk satu kantung darah merah, para calo darah mematok harga $\mathrm{Rp} 400.000$ ) berlangsung dalam waktu yang disebutkan oleh klausa kedua (satu kantong trombosit Rp 2,5 juta)

3) Lantaran terlalu sering mendonorkan darah, suatu hari ia pernah terkapar di rumah sakit selama seminggu. (Kompas/ 01-02-2021/ RPJ)

Pada kalimat diatas terdapat penggunaan konjungsi yang menyatakan kesewaktuan (selama), digunakan untuk menghubungkan dua bagian kalimat dengan makna menyatakan bahwa perbuatan pada klausa yang satu (Lantaran terlalu sering mendonorkan darah, suatu hari ia pernah terkapar di rumah sakit) berlangsung dalam waktu yang disebutkan oleh klausa kedua (seminggu)

4) Karena itulah, ujar Ikhsan, penting untuk tetap memelihara sejarah panjang Kota Palembang agar tidak pupus digilas zaman. Seketika kami teringat pesan Bung Karno, “Jangan sekali-kali meninggalkan sejarah!”. (Kompas/ 11-02-2021/ RPJ)

Pada kalimat diatas terdapat penggunaan konjungsi yang menyatakan kesewaktuan (seketika), digunakan untuk menghubungkan dua bagian kalimat dengan makna menyatakan bahwa perbuatan pada klausa yang satu (penting untuk tetap memelihara sejarah panjang Kota Palembang agar tidak pupus digilas zaman) berlangsung dalam waktu yang disebutkan oleh klausa kedua (kami teringat pesan Bung Karno, "Jangan sekali-kali meninggalkan sejarah!" 
e. Konjungsi yang Menyatakan Penyuguhan

Pada penelitian ini, peneliti menemukan 15 data yang mengandung konjungsi subordinatif yang menyatakan penyuguhan. Berikut data yang menunjukkan konjungsi subordinatif yang menyatakan penyuguhan:

1) Abdul mengaku beruntung karena dirinya tidak ikut terlibat mengonsumsi barang haram tersebut. Meski kerap diperdaya, preman-preman tersebut tidak pernah sekalipun menjerumuskannya ke dalam dunia narkoba. (Kompas/ 01-02-2021/ RPJ)

Pada kalimat diatas terdapat penggunaan konjungsi yang menyatakan penyuguhan (meski), digunakan untuk menghubungkan dua bagian kalimat dengan makna menyatakan 'penyuguhan' suatu tindakan (Abdul mengaku beruntung karena dirinya tidak ikut terlibat mengonsumsi barang haram tersebut) meskipun bertentangan dengan tindakan lain (kerap diperdaya, preman-preman tersebut tidak pernah sekalipun menjerumuskannya ke dalam dunia narkoba).

2) Walau sakit, ia tetap bertekad terus menjadi donor. (Kompas/ 01-02-2021/ RPJ)

Pada kalimat diatas terdapat penggunaan konjungsi yang menyatakan penyuguhan (walau), digunakan untuk menghubungkan dua bagian kalimat dengan makna menyatakan 'penyuguhan' suatu tindakan (ia tetap bertekad terus menjadi donor) meskipun bertentangan dengan tindakan lain (sakit)

3) Meskipun memiliki keterbatasan, penyandang disabilitas juga mempunyai bakat istimewa. (Kompas/ 04-02-2021/ TMY)

Pada kalimat diatas terdapat penggunaan konjungsi yang menyatakan penyuguhan (meskipun), digunakan untuk menghubungkan dua bagian kalimat dengan makna menyatakan 'penyuguhan' suatu tindakan (penyandang disabilitas juga mempunyai bakat istimewa) meskipun bertentangan dengan tindakan lain (memiliki keterbatasan)

4) Impian kami, walaupun anak petani dan putus sekolah, harus punya keterampilan yang bisa diandalkan. Agar kami bisa bersaing dengan anak kota," ujar Dasimto (Kompas / 0502-2021/BKY)

Pada kalimat diatas terdapat penggunaan konjungsi yang menyatakan penyuguhan (walaupun), digunakan untuk menghubungkan dua bagian kalimat dengan makna menyatakan 'penyuguhan' suatu tindakan (harus punya keterampilan yang bisa diandalkan. Agar kami bisa bersaing dengan anak kota) meskipun bertentangan dengan tindakan lain (anak petani dan putus sekolah)

f. Konjungsi yang Menyatakan Perbandingan

Pada penelitian ini, peneliti menemukan 7 data yang mengandung konjungsi subordinatif yang menyatakan perbandingan. Berikut beberapa contoh data yang menunjukkan konjungsi subordinatif yang menyatakan perbandingan:

1) Apabila ada pasien membutuhkan darah dan golongan darahnya sama dengan golongan darah Nur, ia dengan senang hati mendermakan darahnya. (Kompas/ 01-02-2021/ RPJ)

Pada kalimat diatas terdapat penggunaan konjungsi yang menyatakan perbandingan (sama dengan), digunakan untuk menghubungkan dua bagian kalimat dengan makna yang menyatakan bahwa peristiwa yang terjadi pada klausa pertama (Apabila ada pasien membutuhkan darah dan golongan darahnya) sama atau mirip seperti yang terjadi pada klausa kedua (golongan darah Nur, ia dengan senang hati mendermakan darahnya)

2) Apalagi untuk donor apheresis, jarum suntiknya lebih besar dari donor darah biasa, seperti sedotan minuman ringan. (Kompas/ 01-02-2021/ RPJ)

Pada kalimat diatas terdapat penggunaan konjungsi yang menyatakan perbandingan (seperti), digunakan untuk menghubungkan dua bagian kalimat dengan 
makna yang menyatakan bahwa peristiwa yang terjadi pada klausa pertama (Apalagi untuk donor apheresis, jarum suntiknya lebih besar dari donor darah biasa) sama atau mirip seperti yang terjadi pada klausa kedua (sedotan minuman ringan).

3) Teman-temannya mengaku sedang datang ke sana karena udaranya sejuk dan suasananya tenang seperti berada di tengah hutan. (Kompas/ 08-02-2021/ V0)

Pada kalimat diatas terdapat penggunaan konjungsi yang menyatakan perbandingan (seperti), digunakan untuk menghubungkan dua bagian kalimat dengan makna yang menyatakan bahwa peristiwa yang terjadi pada klausa pertama (Temantemannya mengaku sedang datang ke sana karena udaranya sejuk dan suasananya tenang) sama atau mirip seperti yang terjadi pada klausa kedua (berada di tengah hutan)

g. Konjungsi yang Menyatakan Batas Akhir

Pada penelitian ini, peneliti menemukan 19 data yang mengandung konjungsi subordinatif yang menyatakan batas akhir. Berikut beberapa data yang menunjukkan konjungsi subordinatif yang menyatakan batas akhir:

1) Awalnya saya jadi anak jalanan di kawasan Jalan Gadjah Mada, terus pindah ke Pulogadung dan Kalimalang. Pernah saya tidur di Stasiun Gambir, malah dikerjain sama anak-anak di sana sampai dipukuli," ungkapnya saat ditemui di Jakarta, Jumat $(29 / 1 / 2021)$

Pada kalimat diatas terdapat penggunaan konjungsi yang menyatakan batas akhir (sampai), digunakan untuk menghubungkan dua bagian kalimat, yaitu pada klausa pertama (Pernah saya tidur di Stasiun Gambir, malah dikerjain sama anak-anak di sana) dengan makna menyatakan batas akhir suatu tindakan yang terlihat pada klausa kedua (dipukuli)

2) Berbagai hal pernah dia lakoni. Mulai dari mengamen, menjadi joki 3 in 1, menjadi tukang parkir, menyemir sepatu, hingga berjualan kantong plastik. (Kompas / 02-02-2021/ FR)

Pada kalimat diatas terdapat penggunaan konjungsi yang menyatakan batas akhir (hingga), digunakan untuk menghubungkan dua bagian kalimat, yaitu pada klausa pertama (Berbagai hal pernah dia lakoni. Mulai dari mengamen, menjadi joki 3 in 1, menjadi tukang parkir, menyemir sepatu) dengan makna menyatakan batas akhir suatu tindakan yang terlihat pada klausa kedua (berjualan kantong plastik).

3) Tugas utamanya ialah mulai dari meracik bumbu, mengolah masakan, hingga mengusulkan menu. (Kompas/ 03-02-2021/ SRY)

Pada kalimat diatas terdapat penggunaan konjungsi yang menyatakan batas akhir (hingga), digunakan untuk menghubungkan dua bagian kalimat, yaitu pada klausa pertama (Tugas utamanya ialah mulai dari meracik bumbu, mengolah masakan) dengan makna menyatakan batas akhir suatu tindakan yang terlihat pada klausa kedua (mengusulkan menu)

4) Sigit dan Wanggi benar. Tiada mahluk hidup, termasuk primata, ingin diburu atau terkurung. Salah apa mereka sampai harus hidup di balik jeruji. (Kompas/ 09-02-2021/ MWR)

Pada kalimat diatas terdapat penggunaan konjungsi yang menyatakan batas akhir (sampai), digunakan untuk menghubungkan dua bagian kalimat, yaitu pada klausa pertama (Sigit dan Wanggi benar. Tiada mahluk hidup, termasuk primata, ingin diburu atau terkurung. Salah apa mereka) dengan makna menyatakan batas akhir suatu tindakan yang terlihat pada klausa kedua (harus hidup di balik jeruji)

Berdasarkan identifikasi data diatas, diperoleh beberapa jenis konjungsi subordinatif yang terdapat dalam rubrik sosok harian Kompas. Penelitian ini menggunakan teori Chaer. Hasil 
identifikasi diperoleh 139 data yang mengandung konjungsi subordinatif. Berdasarkan pengklasifikasian data terdapat 7 jenis konjungsi subordinatif yang terdapat dalam rubrik sosok harian Kompas. Jenis konjungsi subordinatif, berupa: (a) sebab ditemukan 43 data, meliputi oleh sebab, karena, dan sebab (b) syarat ditemukan 5 data, yang termasuk konjungsi ini adalah jika (c) tujuan ditemukan 21 data, yang termasuk konjungsi ini adalah agar, guna (d) kesewaktuan, ditemukan 29 data, yang termasuk konjungsi ini adalah ketika, selama, sementara (e) penyuguhan ditemukan 15 data, yang termasuk konjungsi ini adalah meskipun (meski) walaupun (walau), sekalipun (f) perbandingan ditemukan 7 data, meliputi lebih dari, seperti, dan sama dengan(g) batas akhir ditemukan 19 data, yang termasuk konjungsi ini adalah sampai, hingga.

Hasil dalam penelitian ini sejalan dengan penelitian Suryantini, meliputi: konjungsi penyebab terdapat 5 data, konjungsi tujuan ada 2 data, konjungsi penyungguhan ada 1 data, konjungsi kesewaktuan ada 2 data, konjungsi pengakibatan ada 3 data, dan konjungsi perbandingan ada 1 data[16].

Kemudian didukung oleh penelitian Melia yang menuturkan konjungsi subordinatif terdapat 102 data, meliputi setelah, agar, jika, sehingga, apabila, setelah, karena, sampai, sebab, kalau, waktu, andaikata, sebelum, walaupun, dan hingga[20].

\section{Simpulan}

Hasil identifikasi diperoleh 139 data yang mengandung konjungsi subordinatif. Berdasarkan pengklasifikasian data terdapat 7 jenis konjungsi subordinatif yang terdapat dalam rubrik sosok harian Kompas. Jenis konjungsi subordinatif, berupa: (a) sebab ditemukan 43 data, yang termasuk konjungsi ini yakni karena, sebab, dan oleh sebab (b) syarat ditemukan 5 data, yang termasuk konjungsi ini adalah jika (c) tujuan ditemukan 21 data, yang termasuk konjungsi ini adalah agar, biar, guna (d) kesewaktuan, ditemukan 29 data, yang termasuk konjungsi ini adalah ketika, selama, sementara, seketika (e) penyuguhan ditemukan 15 data, berupa sekalipun, walaupun, dan meskipun (f) perbandingan ditemukan 7 data, berupa lebih dari dan sama dengan(g) batas akhir ditemukan 19 data, yang termasuk konjungsi ini adalah sampai, hingga.

\section{REFERENSI}

[1] Musyafa'ah, "Analisis Wacana Kritis Model Teun A. Van Dijk 'Siswa Berprestasi Jadi Pembunuh.,"' Modeling, vol. 4, no. 2, pp. 203-211, 2017.

[2] U. Hanifah, "Analisis Framing Tentang Wacana Terorisme di Media Massa (Majalah Sabili)," Komunika Jurnal Dakwah dan Komunikasi., 2019, doi: 10.24090/komunika.v13i2.2053.

[3] C. P. Sari, "Struktur Tematik Berita Penyalahgunaan Narkoba Harian Media Indonesia (Analisis Wacana Kritis Teun A. Van Dijk).," Fon J. Pendidik. Bhs. Dan Sastra Indones., vol. 12, no. 1, pp. 19-29, 2018.

[4] Payuyasa, "Analisis Wacana Kritis Model Van Dijk Dalam Program Acara Mata Najwa Di Metro TV," Segara Widya, vol. 5, no. 2, pp. 2354-7154, 2017.

[5] H. Cangara, Pengantar Ilmu Komunikasi. Jakarta: Rajawali Pers, 2014.

[6] T. Hendra, "Media Massa Dalam Komunikasi Pembangunan," J. at-Taghyir J. Dakwah dan Pengemb. Masy. Desa, 2019, doi: 10.24952/taghyir.v1i2.1723.

[7] H. B. Mardikantoro, "Analisis Wacana Kritis Pada Tajuk (Anti) Korupsi Di Surat Kabar Berbahasa Indonesia," Litera, vol. 13, no. 2, pp. 1-17, 2014.

[8] Suryawati, Jurnalistik Suatu Pengantar. Bogor: Ghalia Indonesia, 2014.

Lala Kartika Sandra dan Dini Restiyanti Pratiwi (Variasi penggunaan Konjungsi subordinatif) 
[9] Finoza, Komposisi Bahasa Indonesia Untuk Mahasiswa Nonjurusan Bahasa. Jakarta: Diksi Insan Mulia, 2013.

[10] R. C. Cenderamata, "Pengnggunaan Konjungsi dalam Surat Kabar Republika Online Edisi Maret-Mei 2018: Suatu Kajian Sintaksis," Suar Bentang, 2019, doi: 10.26499/surbet.v13i2.85.

[11] H. Alwi and Dkk., Tata Bahasa Baku Bahasa Indonesia. Jakarta: Balai Pustaka, 2014.

[12] Y. Maulina, "Penggunaan Konjungsi dalam Wacana Pembelajaran Literasi," Madah J. Bhs. dan Sastra, 2018, doi: 10.31503/madah.v9i2.765.

[13] Chaer, Sintaksis Bahasa Indonesia. Jakarta: PT Rineka Cipta, 2017.

[14] F. Amalia, B. Hartono, and S. P. T. Utami, "Konjungsi Wacana Bahasa Indonesia Pada Wacana Media Tulis (Online), Buku Teks (Pelajaran), Dan Artikel Ilmiah,” J. Sastra Indones., vol. 7, no. 1, pp. 73-80, 2018.

[15] D. Ratnasari, "Penggunaan Konjungsi Pada Wacana Berita Utama Solopos Dan Implikasinya Dengan Pembelajaran Bahasa Indonesia," Publ. Ilm. Univ. Muhammadiyah Surakarta, vol. 3, no. 1, pp. 2-15, 2017.

[16] D. Suryantini, "Analisis Penggunaan Konjungsi Koordinatif Dan Subordinatif Pada Rubrik Hukum Dan Kriminal Dalam Surat Kabar Solopos Edisi Agustus-Oktober 2013,” Dr. Diss. Univ. Muhammadiyah Surakarta, 2014.

[17] L. J. Moleong, Metodologi Penelitian Kualitatif. Bandung: PT Remaja Rosdakarya Offset, 2017.

[18] A. N. Putri, "Penggunaan Konjungsi Subordinatif Kuasal dan Temporal dalam Teks Berita," Jurnal Basindo Kajian Bahasa, Sastra Indonesia, dan Pembelajarannya, 2019.

[19] Mahsun, Metode Penelitian Bahasa: Tahapan Strategi, Metode Dan Tekniknya. Cetakan Keenam. Jakarta: PT. Rajaa Grafindo Persada, 2017.

[20] Melia, "Analisis Penggunaan Konjungsi Bahasa Indonesia Pada Editorial Surat Kabar Tribun Pontianak," J. Pendidik. Bhs., vol. 6, no. 2, pp. 281-293, 2017. 